\title{
A RECEPÇÃO DA LITERATURA BRASILEIRA NOS ESTADOS UNIDOS
}

FITZ, Earl ${ }^{1}$

RESUMO: No presente ensaio, reflito sobre a recepção da literatura brasileira no exterior a partir de minha experiência de anos de dedicação à pesquisa e ao ensino da literatura interamericana nos Estados Unidos e de minhas leituras entusiasmadas da literatura brasileira.

PALAVRAS-CHAVE: Literatura Brasileira; Literatura Interamericana; Recepção da Literatura.

\section{THE RECEPTION OF BRAZILIAN LITERATURE IN THE UNITED STATES}

\begin{abstract}
In this study, as someone who has devoted years to researching and teaching inter-American literature in the United States and as an enthusiastic reader of Brazilian literature, I reflect on the reception of Brazilian literature abroad.
\end{abstract}

KEYWORDS: Brazilian Literature; Inter-American Literature; Reception of Literature.

Ao refletir sobre a recepção da literatura brasileira nos Estados Unidos, tomo por base o argumento indispensável de meu projeto de pesquisa maior em torno da literatura interamericana. Para mim,

\footnotetext{
${ }^{1}$ Professor of Portuguese, Spanish, and Comparative Literature Affiliated faculty: Center for Latin American Studies. Vanderbilt University, USA.

***Texto revisado por Joelma Santana Siqueira, professora de Literatura Brasileira, Universidade Federal de Viçosa - UFV.
} 


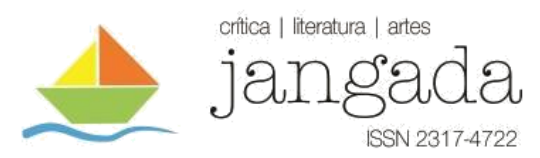

a literatura brasileira é a mais rica, a mais diversa e a mais inovadora do nosso hemisfério. Assim, a questão de sua recepção atravessa o estudo da literatura nas Américas como assunto fundamental.

De imediato, peço desculpas pelo meu modo de escrever que, acredito, seja parecido com o modo como jogo futebol, quer dizer, sem jeito nenhum e com a mesma quantidade de panache (zero), porém, com enorme entusiasmo. Adoro o português do Brasil, mas não o controlo bem. $\mathrm{O}$ meu português vem de livros publicados nos anos sessenta, principalmente o livro Português para Principiantes, do professor Claude Leroy (um dos pioneiros no estudo do português e do Brasil nos Estados Unidos), e é por isto que até hoje ando dizendo "puxa vida!" todo o tempo. Por isso, de novo, peço desculpas! E, também, paciência.

Hoje em dia, tendo eu mais passado do que futuro, faço tudo no espírito do grande narrador Brás Cubas, que de modo notável, disse "a obra em si mesma é tudo: se te agradar, fino leitor, pago-me da tarefa; se te não agradar, pago-te com um piparote”, neste caso, não com piparote, como no caso do Brás, mas com uma modéstia bem-merecida.

No mundo das Letras, a recepção é uma das questões mais complicadas que temos. E também uma das mais importantes, sobretudo hoje, em uma era de comunicação eletrônica quase instantânea. Pelo uso das novas tecnologias, trocamos nomes e textos, mas, frequentemente, sem o contexto de que precisamos. Temos mais e mais fatos e informações, mas não temos entendimento, nem dos autores ou dos textos e nem da tradição intelectual e artística de onde surgem. Saber o nome de Machado de Assis ou Clarice Lispector é uma coisa; entendê-los é outra.

Historicamente, assuntos de influência e recepção eram estudados sob a perspectiva dos textos que exerciam a influência, principalmente os de tradição europeia, sobretudo os da Inglaterra, França ou Alemanha. Isso explica o fato de obras escritas em inglês, francês e alemão terem formado, no princípio, a base da disciplina Literatura Comparada. Esse fato também produziu uma hierarquia das línguas e literaturas, algumas worthy, ou seja, as que produzem textos de valor verdadeiro, os modelos, os protótipos contra os quais todos os outros textos do mundo têm que ser avaliados, e outras, que são automaticamente consideradas de menor importância. E, quase sem exceção, esses "outros" textos sempre ficam determinados (e até predeterminados) a serem inferiores. Não importa nem a sua originalidade nem a sua excelência. Esse problema existia, mesmo nos anos sessenta do chamado "Boom", quando a literatura latino-americana começou pela primeira vez a ser aceita pela classe dirigente aqui nos Estados Unidos. O grande scholar uruguaio 


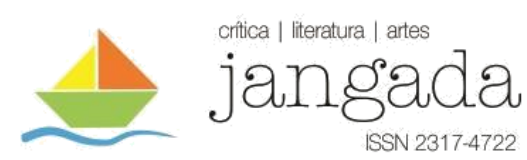

Emir Rodríguez Monegal, desde sua posição prestigiosa como professor dos estudos latinoamericanos na Universidade de Yale, era um dos poucos intelectuais a insistir em incluir a literatura brasileira no contexto maior das letras latino-americanas. Fez isto explicitamente em $\mathrm{El}$ Boom de la Novela Latinoamericana (1972) e depois em The Borzoi Anthology of Latin American Literature, cuja primeira edição é de 1977. Entusiasta e partidário da literatura hispano-americana e brasileira nos Estados Unidos, Monegal expressou a sua frustração com colegas norte-americanos (os predispostos contra a literatura latino-americana) escrevendo, em 1968, que aqui sofremos de um "blind literary prejudice”/“cego prejuízo literário" contra a cultura latino-americana, só com “exasperating sluggishness"/“lentidão exasperante" e resistência intelectual e artística, a literatura da América Hispânica e do Brasil foram recebidas aqui na terra dos Yankees (p. 3; trad. do autor). Monegal continua com o mesmo argumento, citando duas figuras influentes, Edmund Wilson e Lionel Trilling, para quem a literatura latino-americana tinha valor sociológico e não valor literário (p. 3). Os norte-americanos, segundo Monegal, só valorizavam as literaturas europeias. Infelizmente, ele tinha razão.

Uma recepção mais positiva da literatura latino-americana em geral, e da literatura brasileira em particular, teria que esperar por uma geração mais jovem e com uma visão mais aberta, mais democrática e menos cheia de preconceitos. Foi, então, só com os jovens universitários dos anos sessenta que a literatura da América Hispânica e do Brasil passaram a ser aceitas, embora nem sempre bem entendidas pela elite artística e intelectual dos Estados Unidos. Entre os escritores norte-americanos, foi John Barth, bastante influenciado por Machado de Assis no seu romance The Floating Opera (1956), quem primeiro celebrou Machado aqui (FITZ, 1086, p. 186-187). Mas progresso no campo intelectual é devagar, e só hoje, na terceira década do século XXI, escritores como Machado de Assis, Clarice Lispector, Regina Rheda, Nélida Piñon, Hilda Hilst, Carlos Drummond de Andrade e outros estão superando este prejuízo en masse.

Atualmente, questões urgentes a respeito da globalização, exploração política e econômica, racismo e hegemonia cultural estão transformando as lentes pelas quais nós, que formamos uma comunidade global, consideramos e respondemos às várias literaturas nacionais que podemos apreciar. Podemos ver isto aqui nas Américas com o crescimento da nova disciplina que aqui nos Estados Unidos conhecemos como os estudos Interamericanos, ou estudos Hemisféricos. Como brasilianista e comparatista profissional, eu sou torcedor desta perspectiva. E, para mim, literatura, 
história e cultura pulsam como o coração (o coração selvagem, como diria Clarice Lispector) de todo este projeto.

No caso do Brasil, e da recepção de sua literatura nos Estados Unidos, esta pulsação é particularmente fascinante. E tem muito a ver com certos autores e textos, começando com o aparecimento, em 1920, da versão inglesa de Canaã/Canaan (1902), de Graça Aranha, que, se não me engano, foi o primeiro escritor brasileiro a ser traduzido para o inglês e publicado nos Estados Unidos. Para os que gostam da história literária americana e se interessam por questões de recepção,

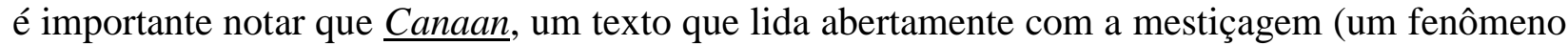
tradicionalmente proibido nos Estados Unidos) e com a questão da emigração, apareceu nos EUA numa época de grande ódio racial e violência contra os afro-americanos e de uma animosidade feroz contra os imigrantes. Também é importante notar que o celebrado crítico Guglielmo Ferrero louvou o livro, declarando-o, na sua introdução, grande romance americano, um termo que, para Ferrero, incluiu a América do Norte e a América do Sul (GOLDBERG, 1921, p. 18-22).

Mais tarde, teríamos aqui outros autores brasileiros, como Machado de Assis, Lima Barreto, Jorge Amado, Clarice Lispector, Carlos Drummond, Graciliano Ramos, Nélida Piñon e até Guimarães Rosa. Hoje em dia, temos também mestres como Hilda Hilst, Regina Rheda, Caio Fernando Abreu, Patrícia Galvão, J. P. Cuenca, João Gilberto Noll e outros. A promoção da literatura brasileira nos Estados Unidos é o meu trabalho principal hoje, nos últimos anos da minha carreira. E posso dizer que o interesse no Brasil, em suas realidades sociais, políticas e econômicas, mas, também, em sua cultura, está aumentado aqui nos Estados Unidos. E isto é de bom augúrio para mais estudos comparativos no futuro.

A popularidade de Jorge Amado continua sendo de grande interesse para brasilianistas aqui nos Estados Unidos. Quando apareceu em uma tradução bem viva em 1962, o romance Gabriela, Cravo e Canela/ Grabriela/ Clove and Cinnamon se estabeleceu imediatamente como um hit, um best seller, e ficou na lista do New York Times de textos mais populares nos Estados Unidos por muitas semanas. Machado de Assis (que tinha existido em boas traduções desde os anos 1950) não tinha esse sucesso, mas Jorge Amado, sim. Como se explica isto? A questão revela muito da complexidade do processo de como se recebe um texto literário em outra cultura.

Temos tido muitas explicações possíveis, oferecidas ao longo dos anos, mas, para mim, duas se destacam: a primeira, mais cultural em natureza, tem a ver com um estereótipo popular que 


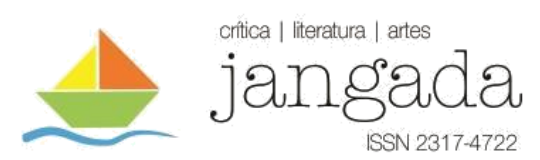

os norte-americanos possuem do Brasil como uma nação de praias, sol e mulheres sexy. Outra parte desse mesmo estereótipo diz respeito ao "proibido", à atração sexual, ao poder sexual da mulher mulata como uma figura desejada, mas proibida na cultura racista dos Estados Unidos. A personagem Gabriela, uma mulata que adorava não apenas o sexo, mas também a sua liberdade, era muito atraente para homens e para mulheres. A segunda explicação é mais artística: o romance machadiano era por demais subtil e sofisticado para os leitores norte-americanos. Nem a inteligentsia americana esperava textos tão polidos e complicados de um autor não europeu e, sobretudo, um autor da "América Latina". Isto reflete o problema de low expectations, ou seja, "expectativas baixas." O mundo apresentado por Jorge Amado era mais aceitável (porque, para o norte-americano, parecia confirmar o estereótipo do Brasil que existia no imaginário), e o estilo do escritor, até em tradução inglesa, era mais fácil para consumir. Com Gabriela, Cravo e Canela, Amado apresenta uma visão positiva do Brasil, uma cultura alegre que (como a dos EUA) tinha também fé na ideia do progresso material. O que resultou, na consciência norte-americana, foi um uma apreciação entusiástica de Jorge Amado, mas uma apreciação superficial do mestre Machado de Assis (que não confirmou os estereótipos do Brasil como uma terra de sol, praias e muitas “garotas de Ipanema” da imaginação norte-americana).

Não quero dizer que Amado seja escritor inferior; só é diferente. É, por exemplo, um grande storyteller, um narrador cativante na melhor tradição oral, com as exceções do sexismo, que às vezes cultiva e a sua tendência a romantizar a pobreza, gosto de Amado. Mas, ao mesmo tempo, adoro e admiro muitíssimo o mestre Assis, a quem considero um craque literário global, um inovador autêntico da arte narrativa, aspecto que discuto no livro Machado de Assis and Narrative Theory (2019).

Tem mais... Durante os anos sessenta e setenta, Jorge Amado era o autor brasileiro que se conhecia aqui nos Estados Unidos. Era bem popular. Essa popularidade tinha a ver, como já notei, com sua representação da mulata como uma mulher que gostava de sexo e de liberdade, a cultivar os dois sem precisar da permissão dos homens. Um exemplo atraente da mulher liberal, Gabriela era popular entre leitores masculinos, claro, mas também entre leitoras, que viam nela uma nova forma de ser. O desejo pela liberdade - sexual, social e política - que marca esta protagonista de Amado confirmava um dos motivos básicos daquele período. Gabriela seria a protagonista brasileira mais popular nos EUA, na página e no filme que foi feito do romance. 


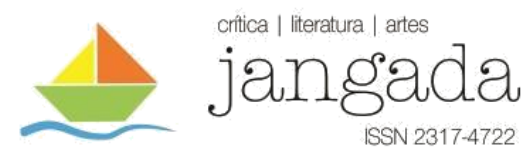

Clarice Lispector, que viu seu romance A Maçã no Escuro aparecer numa tradução bela e tão hipnótica quanto o original, The Apple in the Dark, não recebeu o mesmo tipo de popularidade. Nem Guimarães Rosa, que viu The Devil to Pay in the Backlands aparecer no ano de 1963, no meio do Boom. Talvez porque tinha pouco em comum com os romances hispano-americanos do momento, The Devil to Pay in the Backlands não foi recebido com muita aclamação. No caso deste texto magnífico, o mais importante dos romances que apareceu em todas as Américas durante os anos 1950, havia problemas com a tradução inglesa feita por James L. Taylor, um lexicógrafo bem respeitado, e Harriet de Onís, uma tradutora também estimada. Eu acho que também existia um problema com a recepção de The Devil to Pay in the Backlands relacionado ao gênero artístico conhecido nos EUA como o Western. Sobretudo na década de cinquenta, o Western era uma forma, literária e cinematográfica, muito popular - e muito nacionalista, quer dizer, uma forma associada de maneira muito profunda com a identidade norte-americana. Depois da segunda guerra mundial, e durante o período da Guerra Fria, o Western, como forma artística, cultivava o mito nacional da raça, associado àa masculinidade e poder. Na minha apreciação, é bem possível que os críticos estabelecidos da elite norte-americana tenham tido reservas em louvar um texto do Brasil que parecia desafiar ou prejudicar um gênero tão nacionalista.

Para os que conhecem Grande Sertão: Veredas na sua linguagem original, é óbvio que vai ser difícil, se não impossível, fazer uma tradução que replique o que faz a linguagem original. Quando, em 1984, um crítico tão influente quanto Rodríguez Monegal escreveu que Guimarães Rosa era "beyond dispute Latin America's greatest novelist” (MONEGAL, 1977, p. 679), "fora de qualquer dúvida", Guimarães Rosa "era o romancista mais importante da América Latina", fazia referência não à recepção de Rosa em The Devil to Pay in the Backlands, mas a um outro romance, um que se chamava Grande Sertão: Veredas (trad. do autor). Até hoje em dia, a grandeza e brilho deste texto vivem só na sua linguagem original e não na tradução inglesa de Taylor e de Onís, que, na verdade, fizeram uma tentativa prodigiosa e em muitas partes bem-sucedida.

Pode-se dizer que, em geral, a literatura brasileira tem sido bem tratada no campo da tradução. O mestre tradutor Gregory Rabassa transformou A Maçã no Escuro em The Apple in the Dark e deu-nos uma maravilhosa versão inglesa de Avalovara, de Osman Lins. Rabassa também restaurou as Memórias Póstumas de Brás Cubas ao seu título original com The Posthumous Memoirs of Brás Cubas (a tradução muito boa e mais disponível nos EUA tinha tido o título curioso 


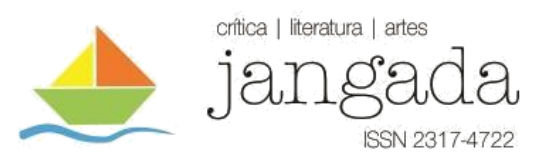

de Epitaph of a Small Winner, de William L. Grossman). Outros tradutores excelentes incluem Samuel Putnam (Os Sertões; Casa Grande e Senzala); William L. Grossman (Machado de Assis); Allison Entrekin (Grande Sertão: Veredas); Katrina Dodson (Clarice Lispector); Barbara Shelby (Jorge Amado); Helen Lane Elizabeth Lowe (Machado de Assis; Clarice Lispector; Rubem Braga; JP Cuenca); e nosso filho Ezra Fitz (JP Cuenca; Fábio Zucar).

Como já notei, a primeira aparição da literatura brasileira nos EUA foi em 1920 com Canaan (Canaã), traduzido por Mariano Joaquím Lorente e publicado pela casa editorial Four Seas Company, de Boston. O segundo texto foi uma coleção de contos brasileiros, editado por Goldberg e levando o título de Brazilian Tales (1921), também publicado por Four Seas. Os contos, compilados e traduzidos pelo Goldberg são três de Machado de Assis, "The Attendant's Confession", "The Fortune-Teller" e "Life"; um de José de Medeiros e Albuquerque, "The Vengeance of Felix"; um de Coelho Neto, “The Pidgeons"; e um de Carmen Dolores, “Aunt Zeze's Tears". O próximo ano, 1922, o famoso ano do Modernismo no Brasil, outro estudo de Goldberg, Brazilian Literature, foi publicado nos EUA pela prestigiosa casa Alfred A. Knopf, de Nova York, uma companhia que seria chave na propagação da literatura latino-americana (inclusive a do Brasil) durante a era do Boom. Não é sem razão que pensamos em Isaac Goldberg como o primeiro brasilianista profissional dos Estados Unidos.

Mas, mesmo que achemos que a literatura brasileira tem se saído bem no processo da tradução (nem todos concordam com esta posição), há duas grandes exceções: Macunaíma e Grande Sertão: Veredas. Ambos os textos são clássicos, columnas da moderna literatura brasileira e merecem novas traduções. Isso está acontecendo. Na sua nova tradução inglesa de Grande Sertão: Veredas, Alison Entrekin está enfatizando a oralidade do texto

O problema fundamental com a recepção da literatura do Brasil nos EUA surge de uma combinação tóxica da ignorância e um ainda forte preconceito geral contra a América Latina. E embora essa situação esteja diminuindo com a chegada de uma nova geração de jovens (gente mais consciente dos preconceitos do passado nos EUA e mais interessada na arte, história e cultura do Brasil), um nível alto de ignorância ainda existe. Temos que mudar isto. E podemos, sim.

$\mathrm{E}$, nesse front, há boas notícias. A geração atual de jovens norte-americanos quer libertarse dos prejuízos do passado (o racismo e o sexismo, por exemplo) para receber o resto do mundo mais como companheiros em uma luta global contra a injustiça. Vejo progresso aqui, e 


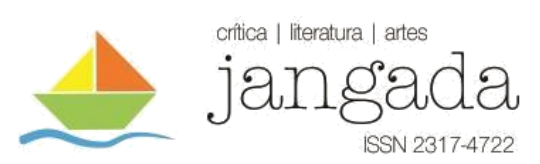

oportunidade também. Mas o peso de um provincialismo histórico ainda nos impede. Como escreveu o grande latino-americanista John S. Brushwood no ano 1987, em referência ao povo dos Estados Unidos:

\begin{abstract}
"We are an intensely provincial people, in spite of the lives and money we have scattered around the globe. We resist foreign literature in general, and this basic position is exacerbated with respect to countries that are not financially or militarily powerful" $\left(1987\right.$, p. 14). ${ }^{2}$
\end{abstract}

Mas os jovens de hoje estão tentando deixar esse provincialismo tradicional, e estão fazendo progresso. O estudo da literatura pode ter um papel importante neste novo rapprochement cultural e intelectual entre o povo do Brasil e o povo dos Estados Unidos.

Com relação ao que nos impede de prosseguir, em resumo, podemos ver três fatores que, juntos, têm militado contra a recepção mais positiva da literatura brasileira nos Estados Unidos:

Primeiro, existe nos EUA um desdém histórico contra a América Latina. Esta situação resulta de dois prejuízos básicos, a religião e a mestiçagem. Os dois datam da chegada dos Puritanos ingleses em 1607 e formam raízes fortes e profundas na época colonial norte-americana.

O segundo problema tem a ver com a visão vaga e muito imprecisa que tem a maioria dos norte-americanos sobre a "América Latina". Para a gente dos Estados Unidos, a ideia ou imagem da América Latina só quer dizer a América da fala espanhola. Nesta concepção errada, o Brasil, com sua história fascinante, sua cultura tão rica e sua literatura brilhante, se perde, ficando, no final, "invisível” para o povo norte-americano, inclusive a classe intelectual e artística.

Terceiro, temos nos EUA o problema da falta de interesse em estudar línguas estrangeiras. Isto é tendência nacional, mas acho que também reflete a continuação do provincianismo que nos tem atormentado desde a nossa fundação. Nas universidades, temos visto, nos últimos vinte anos, um declínio total de estudantes que querem estudar a língua portuguesa, mas também o espanhol, o francês, o alemão etc. E se não temos matrículas robustas, os decanos dizem, mais e mais, que não vai haver aulas de instrução portuguesa.

2 "Somos um povo intensamente provincial, apesar das vidas e dinheiro que temos espalhado pelo globo. Resistimos à literatura estrangeira em geral, e esta posição básica está exacerbada com respeito aos países que não sejam poderosos financeira e militarmente". (trad. do autor)

Jangada| ano 9, nr. 17, jan/jun, 2021 | ISSN 2317-4722

190 | Pá g i n a 


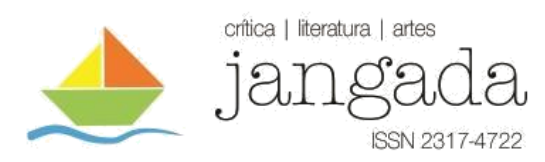

Apesar desses aspectos negativos, temos aqui, como nos casos anteriores, um raio de esperança porque, ao mesmo tempo, estamos nos abrindo ao resto do mundo. Os jovens demandam que abandonemos o provincianismo do passado e que participemos mais da cultura americana e global. E este fato quer dizer que temos agora uma oportunidade para um novo tipo de educação, uma mais comparativa e interamericana, um programa de cooperação entre o governo do Brasil e o dos EUA para educar a gente da América do Norte sobre a cultura brasileira e seu valor aos habitantes desta nação. Não penso em outra manifestação das "relações públicas", mas um programa sistemático e estendido de educação mútua. Acho que esta ideia tem possibilidades, sobretudo hoje na época do globalismo e de um novo espírito de Americanidade. O Brasil e os EUA têm tanto em comum e tantos paralelos históricos que o tipo de educação unificante de que falo aqui pode ser beneficiário a todos. Pensando para a frente, para o futuro, as relações entre o Brasil e os EUA vão ser mais e mais importantes, aqui nas Américas e no exterior global. Estamos vivendo um momento de grande oportunidade, e acho que devemos aproveitá-lo. Identifico outra esperança na tradução. E quando uso esta palavra, não estou pensando apenas nas traduções da literatura brasileira, mas, também, na tradução dos textos de economia, política, história, e, sobretudo, meio-ambiente. Existe nos EUA, acho eu, um mercado para esse tipo de livro, lidando com o Brasil, mas em um contexto nacional, americano e global. Acho também que este mercado está crescendo e devemos jogar a bola, driblando, para frente, juntos...

\section{REFERÊNCIAS BIBLIOGRÁFICAS}

AMADO, Jorge. Gabriela, Clove and Cinnamon. Translated by James L. Taylor and William L. Grossman. New York: Alfred A. Knopf, 1962 (sixth printing in 1970).

ARANHA, Graça. Canaan. Translated by Mariano Joaquin Lorente. Boston: Four Seas, 1920. BRUSHWOOD, John S. "Two Views of the Boom: North and South". In: Latin American Literary Review, Special Issue, "The Boom in Retrospect: A Reconsideration," Yvette E. Miller and Raymond L._Williams, editors, vol. XV, num. 29 (January-June, 1987), p. 13-31.

FITZ, Earl E. "Brazilian Literature in English Translation." In: Brazilian Narrative Traditions in a Comparative Context. New York: Modern Language Association, 2005, p. 152-156.

. "From Casmmuricity to Misanthropic Hermitism: John Barth's Brazilian Connection". In: New World, vol. 2, nos 1 \& 2 (1987), p. 123-138.

"The Influence of Machado de Assis on John Barth's The Floating Opera." In: The Comparatist, vol. X (May 1986), p. 56-66. 
. Machado de Assis and Narrative Theory: Language, Imitation, Art, and Verisimilitude in the Last Six Novels. Lewisburg: Bucknell University Press, 2019.

GOLDBERG, Isaac. Brazilian Tales. Translated and with an introduction by Isaac Goldberg. Boston: International Pocket Library, 1921.

PATAI, Daphne. "Machado in English.” In: Machado de Assis: Reflections on a Brazilian Master Writer, Richard Graham, editor. Austin: University of Texas Press, 1999, p. 85-116.

MONEGAL, Emir Rodríguez. El Boom de la novella latinoamericana. Caracas: Editorial Tiempo Nuevo, 1972.

. "The New Latin American Literature in the USA". In: Review '68. New York: The Center for Inter-American Relations, 1969, p. 3-13.

The Borzoi Anthology of Latin American Literature, vol. 2. New York: Alfred A. Knopf, 1984, $2^{\text {nd }}$ printing; $1^{\text {st }}$ printing, 1977. Emir Rodríguez Monegal editor and author of introductions, with the assistance of Thomas Colchie. 